Edward ROBBINS

\section{Rethinking public space: a new lexicon for design}

\section{Introduction}

If we are "to start a debate about the importance of well planned, maintained and designed public open spaces and their effect on quality of life in urban areas," as the conveners of the conference "Public open space" held in Ljubljana 10-11 April 2008 suggested, I would argue that we should reconsider exactly what we mean by "public space." Many would ask, why bother: isn't it a relatively clear-cut proposition? If only this was the case. The concept of "public space," however, is anything but. Rather, it is at best an ambiguous and effectively overdetermined concept; it refers to so many different qualities, conditions and practices that the discussion and design of social space is often an intellectual as well as a practical muddle; a muddle that we should try to rectify. One way to do this would be to develop a more precise and nuanced lexicon for dealing with the uses of space and place.

Our confusion about public space surfaces when we survey the many divergent uses to which the concept has been put. ${ }^{[1]}$ For many analysts, the discussion of place is framed abstractly with little or no sense of an actual physical landscape. Even when social theorists, even geographers, use the concept, it is used primarily conceptually as shorthand for what they see as particular social locations rather than as an actual description of a physical and grounded landscape. It is more an idea about socio-spatial practices and less a sense of spatial form and spatial qualities. For others public space is crucially a physical landscape. Add to that the many different ways such landscapes are envisioned and the effort to delineate just what public space is grows more problematic.

So many discussions of public space are filled with contradictions and conundrums. Take, for example, the most interesting work of the sociologist Fran Tonkiss (2005). Her discussion of the city provides many informative and clear insights about the politics and sociology of space. When she confronts the issue of public space, however, her work becomes muddled. While she makes much of the different ways public space can be envisioned and the different forms, at least social forms, it takes she leaves us with more questions than answers. In arguing that there are three ideal types of public space: 1 ) the square representing collective belonging; 2) the café representing social exchange and 3) the street representing the informal encounters of everyday life, Tonkiss appears to be giving public space its due. She leaves us though with a series of questions, which go unanswered. Why does the urban square, which is often restricted in its use, or indeed even private in ownership, represent collective belonging? Why are cafés, which she readily admits are privately owned, important settings, indeed an ideal type, of public social exchange? And, what is a public street in a world where increasingly informal encounters occur in malls and other such private places? Nor does Tonkiss help us understand what criteria we should use to understand whether one or another private space acts as a public place. Why, for example, do many commentators see cafes as centers of public discourse while rejecting shopping malls as sites of true public engagement? And finally, and what would be most disappointing to designers, her work does not engage the realities of the space as a palpable socio-physical construction. Questions about such things as the social choreography of the space (the form and substance of the movements of people in the space); its spatial configuration (its shape, its location, its furniture and its surrounding context); its organization in practice (divisions between the less and the more shared areas) and most critically how it is claimed and by whom are effectively ignored. We are left with images of space potentially useful for social discourse but insufficient if we are to actually design it.

My argument is not with Tonkiss. I use her work because what is a most intelligent discussion falters when confronting the challenges posed by "public space." This is illustrative of a current trend in thinking about public space, a refusal to confront the ambiguities and ambivalences associated with the term and a lack of physical concreteness about its socio-spatial forms and configurations. What I am interested in pursuing is the nature of public space as real, effable, and physically grounded place. What interests me and what I want to pursue further in this paper is the question of whether we need a new lexicon, ways of describing what we call "public space" and if so what, at least suggestively, that lexicon might be.

\section{Site and place}

One basis for the confusion that revolves around what constitutes a public space is the range of meanings and practices associated with the spaces that we see as sites and places. Site and place encompass a wide array of conceptual and intellectual constructions; e.g., notions of neighborhood, historical sites, and landmarks. They frame almost all our social practices; e.g., movements, meetings and uses. And site and place are created through the deployment of many different physical forms; e.g., openings, closures, transparencies, obstructions. The key is always to keep in mind that site and place are not only conceptual models of particular social and political locations but they are also physically grounded landscapes. And all are socially constructed. If designers accept the idea that site and place are made up of qualities that are socially constructed (Cresswell, 2004), then the critical questions to address are what these qualities are and how, by whom and for whom these qualities are constructed.

As Margaret Kohn (2003) points out places and sites help to order the social practices by providing scripts for encounter and assembly, for everyday activity. Space as place also serves to create a physical presence of a remembered past, or celebrate a cultural present. By fixing patterns and boundaries of various practices and modes of living - work, home, 
recreation - the organization of everyday life and the way it is located in spaces of separation, and inclusion appear natural and essential. We often experience socio-spatial relations as inevitable; as "just the way they are." The way sites connect to the present or change the past as architecture, as spatial arrangement, or as monument are often defined through space; for example, the way gentrifiers announce their arrival through their boutique windows, café designs, and door and window treatments, are important elements of physical space. Or the way large plazas suggest places of power. Spatial sites set out rules of exclusivity, of permissiveness for certain behaviors or practices, of social interaction (rules about diversity). Or, if they do not set out rules as such they allow for certain dispositions of practice or behavior. Site and place also provide critical locations for claims about identity, and use by various different groups. Indeed claims about place at times have led to brutal conflicts - think of the Dome of the Rock and Wailing Wall in Jerusalem or the role of turf in the public parks of many cities.

This variety of spatial forms that constitute sites and places are embodied in the language we use to describe the different types of social spaces we encounter. Borrowing from Kohn (2003) again there are different words used to depict space abstractly - location, place, milieu, position, structure, nodal point and locality. There are words that designate potentially identifiable locations - neighborhood, road, town, village, city, workplace, and nation. And then there are terms that designate places strongly marked by their association with specific social formations - turf, home, cyberspace, nation, and global market among others. These markers can overlap in the same space - you can be situated in a local turf that is located in particular city that is part of a nation that is shaped by the global market (Smith, 1996).

On the one hand, as again Kohn argues in common with other social theorists, physical space in the form of the landscape provides a setting or backdrop for a set of habits through which we come to define and come to know our social roles - "where people come to know their place." We are positioned socially in space everyday through such things as whether our office has a window or not; whether we are seated at what are considered the best tables in a restaurant; and whether we are allowed into the inner sanctums of city hall or a legislature. These place based attributes are not merely backdrops as is commonly claimed but a set of practices, spatial practices, that are as integral to social life as the practices they are presumed to scaffold.

On the other hand, making the issue potentially more complex and even ambiguous is that physical space - the physical embodiment of social relations - and physical location may have little to do with one's sense of place. Borrowing from my reading of Heidegger (1975) notions such as home may have little in the way of grounded physical form. There is a difference, for example, between home and dwelling. One can be at home in many places other than where one dwells. In other words, the physical location may not be home in the more profound sense of the term. Think of refugees living away from their native land, their address in their adopted country may be a place where they dwell for the moment but their native land is home. In a similar way, our claims to public space may have little to do with our actual use of that space. It may define an important space of memory, a space of commemoration or a space merely to do commerce even though we might have little or no thought of ever actually visiting that space; think of the debates regarding Ground Zero in New York.

Site and place thus are as varied as the many socio-spatial conceptions and practices that are used to construct it. If we add the notion of public, which as we shall see is at best another ambiguous term, to the varieties of site and place, the notion of "public space," or what is a shorthand for what are public sites or places, we will find it is too woolly and too general to be of use in the design of place (see Brodin, 2006). Spatial forms and locations cannot be understood in isolation from the structures, and relations which make the space what it is. Spaces get designed, built and defined through a confluence of social, commercial and political practices which set out a pattern of uses; or attitudes about class, race or ethnicity. These in turn create a blueprint that limns who can use what space, and when and where. Ideally of course, the public space is one that is open to all, that is free and that provides a place for difference and otherness, and where strangers meet even if only passing in the night (Sennett, 1976; Young, 1986). But the problem we face when designing such spaces is that this is not always indeed is usually not the case. Public spaces take many guises, some of which although relatively open to everyday use and interaction are from a legal perspective private and some of which although exclusive and restricted are from a legal standpoint public. The ambiguity and indeed the ironies we face, when we try to define what is public and what is not, is only one piece of the puzzle. Our task is made even more complex when from another perspective - one critical to thinking about the good design of "public space" - we engage the multiple users of a given "public" space and its many different potential uses.

\section{Rethinking public space}

To address "Public space" is first to rethink it. If something is contained, no matter what the particular boundaries of that containment, it can only be held materially by one body at a time be that body an individual, a group or some built form; thus by definition it is always potentially contestable and thus always political. In a society which defines buildings and places by reference either to its public or private character, the politics of space becomes even more complex as space is characterized not only by its social uses but also by its material or abstract value. This complexity, however, is often hidden and obscured by reference to a lexicon which defines only a private or public domain rather than the multiplicity of spatial and social domains and abstract values and claims that are implied by private and public. Certainly public and private exist if only as, on the one hand, legal categories, and on the other, as representations of rather complex social and cultural patterns of spatial understanding and use. But, the complexity of forms that those domains take and the multiplicity of social attributes and meanings that are implied by this division suggest that maybe a rethink of the notion of "public space" is in order. 
Such a rethinking is also made necessary not only by the political nature of space but also because of the ideologically loaded nature of the notions public and private. Public and private suppress and even at times hide the politics so central to the formation of socio-spatial practices by appearing to be natural categories through which to represent the spaces and places of our social and cultural world. They essentialize a distinction that is particular to certain political-economic and social arrangements. Our sense of space and place, in contrast to societies in which the characteristics of space are defined by its social uses alone; it has no abstract value (Auge, 1995). In the latter case space is more flexible, shifting in terms of use and not limited by a set of abstract claims and qualities (Robbins forthcoming) Private property is not found in all societies and its meanings vary even in our own society (Hann, 1998). By using such general concepts, it often conflates different socio-spatial relationships under the same rubric and says little about the actual form the space takes. It conflates ideas about the space of the group and the space of the individual, space defined in terms of ownership and space understood in terms of possession through use; it conflates space as a putative general condition or image with space as a domain defined by specific and local socio-cultural practices. In speaking about the urban, Zygmunt Barman argues the:

Realities of city life play havoc with neat divisions. Elegant models of urban life and sharp oppositions deployed in their construction may give a lot of intellectual satisfaction to the theory-builders, but little practical guidance to the urban planners and even less support to the urban dwellers struggling with challenges of city living (Bauman, 2003).

What is true for the city; the location of most of the challenges faced by those designing and planning what we call "public space," is equally true about the distinction between public and private. Let us look at some examples.

The notion of keeping something or someone in view has for a long period - even today in some circles - played an important role in defining the class attributes of specific actors. In this sense of public/private, there is a peculiar shift away from the notion of public meaning an open social gaze and discourse to one which refers to a restricted gaze and the discourse of people of importance, of office and wealth. They most often hold sway not in the public arena as we commonly understand it but in ironically places that are restricted - private clubs, corporations and in the inner dealings of government. Public discourse, so-called, occurs to a great extent in private and in what has been called the "corridors of power." Public position in this sense is privileged and is located in restricted settings invisible to the common person. At the same time, when we speak of the public we often mean something open to and shared by all. It is the very opposite of privileged or hidden. Public golf courses or public parks are at least putatively free from social restrictions that would limit their use to only certain members of society. Membership, the right to use or access the space in the more general sense of public is commonly held if not necessarily commonly used - what is interesting or attractive to one member of the public may not be to another. It is an issue of open access (if not monetarily free access as in the case of many public parks) and common belonging.
This blurring of what is public and what is private in political and social life is accompanied by similar blurring of these concepts by the conflation of the notions of civic and social interaction with the issues of spatial and place based boundaries, privilege and possession. For example, when applied to a private or public house its uses are fundamentally unclear; the former referring to a dwelling of persons in their familial capacity and the latter referring to a place where business is done and is open to the general community. But in both instances the house or built form can be private in the sense of belonging to someone even if it is more or less open to use and access; of course these are defined by those who own the place. Indeed, social housing presents just such a situation. It is owned by a public entity; i.e., the state. But each dwelling is private; i.e., the leasehold of the tenant. A public house in Britain, what is essentially a pub, does not generally allow for the use of children; indeed in earlier periods it did not permit entry to women. And, to confuse things further in many public houses there are private bars. Another example, a public building like the White House meets none of the general requirements that are associated with the notion of public except that it is a civic building where "public matters" are dealt with. Otherwise it is restricted, reasonably secluded, and closed to the general public. And what do we make of private spaces such as a sports stadium or convention center serving as a public good. Although, designers are wont to describe public space in more generous terms than private space because the latter implies exclusivity, of privilege and possession, private spaces in many instances in today's world are often less exclusive, and more accessible than those that are putatively public. The contrast public/private does not really help us here. Rather in all the cases here, it mystifies rather than clarifies. What is open and what is restricted, what degree of participation or accessibility is more or less public in an age where so much of our communal or social practices are played out in spaces and places wholly owned by private individuals or corporations - malls, stores, theatres - and where so many civic spaces are restricted is at best ambiguous. Where private ends and public begins is a layered and complex reality in our society. What is common, who defines it and how it is to be realized through and in space and place are contested terrains of discourse and practice. One group's notion and practices are not necessarily another's. Whose practices should be allowed on the street, who should be allowed to do what and in what places and spaces is a continually evolving and contested issue.

Equally as critical, with the growing importance of technology in our lives, what might be construed as a kind of space of one's own, as hidden, and inaccessible to others is spatially suspect. The capacity of high-tech devices for surveillance to penetrate almost all forms of space, suggests that privacy as a form of spatial seclusion will have to find another form and a new meaning; spatial inaccessibility will not suffice. There is no longer the possibility of being guaranteed a "room of one's own" in any literal physical sense. Indeed, even where we are not surveyed technologically, the proliferation of glass, the transparency of so many buildings has opened up what were previously visually secluded and inaccessible places and made moot the division between the inside as private and the outside as public. Such changes have rendered conventional notions of private/public irrelevant to our modern existence. 
For designers in need of programmatic instruction or guidance, referencing public or private will provide little in the way of insight. The public/private opposition suggests seams between worlds that in our everyday experience are often seamless There is a pretence of clarity where there is more often opacity about what the space is and who it is to benefit; division where there is overlap, and a suggestion of simplicity where there is mostly complexity. So, what good are public and private as notions about space and place when they obscure rather than reveal, flatten our world rather than layer it and prevent us from seeing the world and its spaces in all their complexity and mutability? Not much, yet the terms persist because if they do not tell us much about our place in the world, and our practices in place, they allow certain political and ideological precepts to remain unchallenged. Most crucially they allow for a notion of public good to remain associated with a general public even as that public has less and less to say about the design and use of its spaces, even as that public is more and more diverse with different and often conflicting ideas about what is appropriate practice on our shared spaces.

If we do not rethink and specify the concepts of public and private, they serve as mystifications hiding the realities which they appear to describe. To refer, for example, to a corporately held space devoted to the pursuit of profit, even if it is open to the general populace for what is in most ways public use e.g. like the atrium of the IBM Building, as public space is to mystify what that space is. Although apparently open, it is ultimately at the sole disposal of that corporation. Further, it is not created though an open and shared political discourse but through closed corporate decision-making. Certainly, civic authorities can make such spaces attractive to corporations through the political process. It can offer tax rebates or provide an extended FAR. And, the space might be quite attractive and useable by the community, but in the final analysis because it is corporately held it implies no commonweal or community at large to whom the space belongs and from whom the space receives its meaning. To use a corporate space, no matter how open, is to consume that which is made available to you by the corporation. It is socially useful but as an extension of corporate largesse and control. To lay claim, or to occupy a corporate space that is prohibited for example is to challenge the rule of property. It is trespass. A public space though is one, at least in principle, that is ultimately under the control of its citizenry. To use it is to lay claim to your rights and responsibilities as a citizen. Even in authoritarian societies where the citizenry have no power or authority, the government held space is different from the corporate space. To lay claim to these spaces in these societies implies wholly different meanings. To lay claim to a prohibited government held space or to use a space in ways not allowed, as for example, the Mothers of the Disappeared have done in the Plaza de Mayo in Buenos Aires is to challenge the very core of the government's legitimacy. The physical occupation of the Plaza is not only an opening up of a physical place; it is an opening of a political space (Schirmer, 1994). It is a profound expression of resistance.

We, in the USA, live in a society that is divided by class, ethnicity, race, religion, gender and a whole series of individually held identities. Although many of these divisions e.g. class, wealth, power, are hierarchical, we are also a society which holds that we have equal rights and we are equal in the "public realm." This raises two crucial contradictions in everyday practice. For one, with the conflation of private and public, the issue of equality is made problematic at best. Equal though we are in the public realm, we are not all equal in places that are privately held or owned even if supposedly for public use. Private ownership of such public/private spaces can place limits on what we do, how we do it and who can do what in the place. Just spend time in a place like Bryant Park in New York City controlled by a BID that provides what appears to be an open and un-adjudicated space but which in reality is heavily securitized and controlled - only some members of the public are truly welcome. In public spaces, though we are putatively equal, restrictions set by government makes us significantly unequal - just try entering a government building, or facility. For another, in what we call public or civic places, we are presented a perplexing problem. We are different, and we are not only strangers but strangers who often act differently and come to a place with drastically different understandings about what is appropriate behavior, what is the correct social etiquette, and what rights we have to that place. Yet, at the same time, we believe ourselves to a part of demos and one in which we are all created equal. This raises a problem of procedures - what procedures are appropriate and how should people putatively equal yet often of different class, wealth, authority and power interact in so-called public place. Can all use a space/ place as they choose? If not, whose procedures for acting, whose practices, whose needs or desires should be given most weight and how is this to be adjudicated?

This is why what we call "public place" creates so much uncertainty, tension, instability and conflict. So much so, that it is a sad reality that so many of our public places go unused. Our urban streets, with a few exceptions are generally empty. Certainly this is partly economic: so many of our daily needs are better met at malls than on our streets. But the desire for malls I would argue and the economics that drives them also comes for our desire to flee the streets of our cities because of our view of them as unsafe and uncertain. We find more social solace and security in the private than the public. As Anthony Vidler (1986) points out in his "Scenes for the Street" as societies became more open their street life becomes riskier. The street rituals and carnivals of previous periods become problematic in a democracy as the controls of aristocratic society no longer obtain. Differences cannot be ritually played out on the street for fear that these rituals of difference will result in real conflict. In aristocratic society, where everyone knows their place, and this is often manifested through what each individual wears, the streets, parks and other "public domains" can be open to all because each has a different space and location in the public realm. This is known and played out. The public realm here reinforces the secure order of society even as it opens up the society to its differences. In a demos, ideologically hewing to a notion that we are all equal, people do not know their place, and thus the public realm of difference becomes a realm of constant tension and potential disorder; as a result we seek the private.

To overcome or assuage fear and uncertainty on the part of some usually influential social groups, those in power, often 
with the complicity of many of us, provide us with what Steve Flusty (1997) calls "interdictory spaces" in our parks, our civic plazas and squares and on our streets. These are spaces that designed to intercept, repel, exclude and segregate would be users of one kind or another. These spaces are not walled or fenced in obvious ways. Rather through what Flusty calls "slippery spaces" or "prickly spaces" among others, certain practices, or groups of people are effectively kept out. Slippery space makes it difficult to find how to get into a park or other supposedly common space; parks with entrances that are well hidden; corporate plazas ostensibly for the public but which must be accessed from the back of a building for example. In the case of the prickly space, the use of such things as hedges, berms and the like make lying down or picnicking difficult if not impossible. This discourages those for whom space should allow for greater activity than just walking and looking.

This is not to say that people in our society do not use our streets, parks and other public places. We do. It is also not to claim that we are incapable of sharing space with those who are different. Clearly for the most part we can and do. But what we do, when and where we do it and the practices and the conditions that describe or name the procedures or understandings are not inherent to the concept public. While indeed we might easily argue that conceptually and philosophically publicness and privateness are indeed critically different, and even provide a degree of both conceptual and ontological clarity, publicness and privateness do not clarify much about space and place. Public and private as socio-spatial concepts reference perhaps more attributes but suggest less of substance than they do for philosophers and other social theorists.

It is for this reason that designers and planners; especially if they are to adequately deal with the implications of any socio-spatial design or decision, need a lexicon that opens up our procedures, and our understandings. Or put another way, it would be a lexicon that allows designers to confront the range and variety of practices that are associated with the social use of space; if not to change practices and qualities at least to be clear about what they are. A language for the design of social space should be one that eschews ambiguity, that rejects hiding complexity in a false simplicity and that reveals rather than conceals. What follows I would like to suggest is just a beginning in to address this issue.

\section{A new lexicon}

Rather than talking about public/private spaces and places we might begin to use more grounded and specified categories or concepts. First and foremost, why not use the concept social space rather than public or private. I suggest this term because it is inclusive; it presumes little about the ontological status of the space and carries little or no ideological baggage. It refers to those spaces that we use as groups and that involves collective - be they communal, cooperative or conflictive - activities, exchanges and practices. To speak of social space is to make no judgments about the quality of the social practice or space, and no claims about to whom and how the space should be made available. "Social space" merely references the many and different societal practices (including perceptual acts) which various and sundry collections of people and even different individuals deploy in space and place. By speaking of social, we avoid the baggage of the concepts public/private. Yet, we can still describe the qualities that we would or want to associate with these concepts. Thus I would argue, why not specify precisely what we are referring to - this will make the designers task, if not easy, clearer and more direct.

There are of course different ways to set out a lexicon for socio-spatial practices; no one approach is "right" in some meta-conceptual way. What I would argue though is that if we keep to a lexicon that sets out practices, either material and/or symbolic, we will develop a descriptive armature that is relatively intersubjective in regard to what it delineates if not in the responses to which it might give rise. An intersubjective lexicon makes possible, if not agreement, a meaningful and nuanced dialogue.

Allow me, albeit if briefly and incompletely, to suggest some terms that might make up such a lexicon. What I offer are examples of the way we could begin to develop terms for our new lexicon. I do not purport to have developed a full and non-negotiable lexicon. Indeed, if I did then it would negate the very spirit of the type of lexicon I am suggesting; a lexicon that provides grounded guidance for the design of social spaces but one that is also open to emendation and that provides categories that promote rather than dampen dialogue. What follows then are some suggestive terms for this lexicon to begin this discussion.

\subsection{Ownership, possession, inhabitation, occupation and use}

I remember when I was in India; I was in market that was surrounded by a number of very active pedestrian streets. During the day, people walked everywhere on these streets stopping to look at or buy goods, mostly jewelry; they appeared to see all parts of the street as open to their use and occupation. Merchants placed their wares outside their stalls, occupying and in a sense inhabiting the edges of the street that bordered their establishments. At certain points on the street, homeless people had left their nighttime bedding and kit in piles that appeared to be associated with those points; one merchant even told me that he would watch those kits during the day. At night, when I returned, the use of the street had changed. Bedding had been set out and people walking on the street who during the day appeared to use the street in a sort of relaxed even careless way, now walked in a more measured way avoiding the bedding of those who later would sleep on the street. There was clearly an understanding that the patterns of possession, occupation if not ownership had changed. The social nature of the space, who had claim to it, shifted from the day to night. Similar patterns of use and occupation can be found in cities like Addis Ababa in Ethiopia and even parts of New York where the homeless stake claims to occupation of various benches and spaces in parks as well as bus and railway stations. 
A friend, a planner from San Francisco, related a story, possibly apocryphal, to me that raises similar issues. At a park in one of the hipper neighborhoods a group of neighborhood residents organized a community based meeting to discuss the use of the park; its hours of occupation, the activities that would be encouraged and the like. The meeting was attended by city authorities, local residents; most of who would portray themselves as socially liberal even modish, as well as homeless people and prostitutes. Most residents though objected to the attendance of the homeless and the prostitutes arguing that they were not entitled to join the discussion about the parks; they were not taxpayers and had no right to possession. In response, the homeless and prostitutes argued that they were indeed stakeholders. They inhabited and used the park more than the residents, they were citizens, and they were members of the public. Indeed, they were equal to if not more important holders of what was they argued a "public space." Residents countered that the homeless and prostitutes were not members of a legitimate public - and so it goes. As the friend who told me the story pointed out, the problem with the word public is that it doesn't have obvious and agreed on attributes and meanings. Indeed, he suggested that the homeless and prostitutes were right; legally they were of the public and indeed did more to maintain the park than others because they used it more. Politically though civic authority rejected their claim. In the end, acrimony destroyed the effort to improve the space.

These stories raise significant questions about the lexicon one should employ when defining a space, who the potential stakeholders of the space are and what their stake is, who has claims to the space and what kind of claims they have. It is an issue whenever designers organize a participatory exercise in an effort to involve the "public" in the design of a shared social space. It is problematic in two ways: 1 ) it is never clear who exactly constitutes the public; 2 ) and it tells us nothing of the different ways a space may be claimed and defined. These two attributes are of course very much related.

A space not only has many "publics," if I may, but is claimed in different ways. A space may be owned, possessed, inhabited, occupied or used. They often overlap but they are not the same. Many social spaces are owned by either government; e.g., a mall or park, or some corporate or other entity; e.g., a shopping mall or café. Owners may have strong ties to the space or may only see it instrumentally as a place to provide services or be kept secure (the government) or to make a profit (private owners). Their sense of what the space might be and how it might be designed will often be limited to these concerns. Others might in effect actually possess the space - park attendants or store owners in a mall. Still others might inhabit it like teenagers or older folks in a mall or local park; or they may occupy it at various points in the day or only use it even in ways that do not mean occupying the space; e.g., parents sending their kids to a park to play, a park the parents never occupy. If we are to design a space, we should be aware of these dynamics. If we are not, at best we can only design a kind of generic space. This might work or but its success is effectively a crap shoot.

\subsection{Open and closed/secluded and accessible/ inside and outside}

The notion open public space is also problematic in a number of ways. And it is for this reason that again we need a more precise lexicon that limns just what we are talking about. When, for example, may a space be considered open; does it have to, as our story above suggests, be open to all potential users? Should be open at all times? If the answer is that it is public the answer is should be yes. But of course we know that no such ideal condition is met for many different reasons. Spaces even if officially and legally open are often closed at specific hours to prevent crime or provide for maintenance. In other spaces, its use by one or another group may be threatening to others. For years, few people used Morningside Park in New York inhabited as it was by gangs and felt to be dangerous by many people; so too Central Park at night. The irony is that if you bring in police or use cameras to create security this of course prohibits other members of the so-called public. That is unless one has a hidden vision of who constitutes this public; e.g., a particular class or ethnic group for example.

When I was a young student in Brooklyn, the schoolyard was a favorite place to play various sports. It was officially locked though in the evenings and also on week-ends and other school holidays. It was a closed space during that time. Or was it? Young boys and girls would enter the yards by climbing fences, by cutting holes in the fence or by breaking the lock. In some instances, where I played for example, the school authorities ignored the holes, and effectively allowed play to continue even during the hours the school yard was officially closed. This of course, taken a step forward, has important implications for the design of the school yard. For example, if you want it to be entirely secure, how you fence it, how you lock it becomes a critical issue; which I would argue also effects the overall feel of a place when it is "open." If you ignore the official closure and allow people to use the yard then you need to think about other issues of use and how the yard can be maintained informally and which aspects of security are more or less important to the overall maintenance of the school. A different sense of use and occupation suggests a different set of designs. I am not arguing that one way or another is the right one. I am arguing that by deploying general terms like open and public we cannot really address the designs that would be more or less appropriate in different situations.

Similarly, with notions of public as accessible or secluded! We can have open public space that is actually totally inaccessible and we can have closed spaces that are easily accessible. That is one point made by Flusty. If we put cameras in secluded social space can we really think of it as secluded? And if we make a space that is open yet inaccessible is it really open? We need to be able to think in terms of not only open public space, but open or secluded in what ways; e.g., secluded in the sense of quiet, in the sense of no official gaze; secluded in a broadly visual sense. And open to what habitation, and occupation and to whom; anyone, athletes, walkers, picnickers? Each of these users may require a different socio-spatial program and design. If we are honest we need more than the notion open and public if we are 
to confront the nature of shared social space. We need a language which sets out a lexicon that includes open but then adds a series of critical amendments; open for, open to; open from; and such where we can bring in the issues of claims, uses, patterns of possession, inhabitation and occupation and such. We need to be more forthright about what we want the space to be and how it will serve various segments of society; even honest about whom it will not serve. The same holds for the idea of closed.

\section{Conclusion}

I have offered a few examples and I could go on but I hope the point is made. Our lexicon should be one that is descriptive and not normative and that nuances social space. It should include the terms I have suggested above and more. And it should be based on our experiences with social space and not fundamentally based solely on philosophical and normative discourses about notions of space; albeit important in larger abstract political discussions but of little use in the design of space.

Indeed, if designers and such begin to use a more grounded lexicon, it might even broaden the political discourse which in many ways could be criticized for its avoidance of real specificity in speaking about the nature of public discourse. The objects of design might not only let us better our design of social space but broaden our philosophic and political discourses about what a public is, where it is to be grounded and when grounded how it should be realized.

Dr. Edward Robbins, Professor

Institute of Urbanism, AHO, Oslo

E-mail: edward.robbins@aho.no

\section{Notes}

[1] The argument is based substantially on Anglo-American sources. I would argue though its suggestions and conclusions, mutatis mutandis, are relevant to the design of public space and place throughout the world.

\section{References}

Auge, C. M. (1995) Non-places: An Introduction to the Anthropology of Supermodernity. New York, Verso.

Bauman, Z. (2003) City of Fears, City of Hopes. London, Goldsmith's College.

Brodin, J. (2006) The Structure of Public Space. Paper Delivered at the Annual Meeting of the Midwest Political Science Association.

resswell, T. (2004) Place: A Short Introduction. Oxford, Blackwell.

Flusty, S. (1997) Building Paranoia, in: Ellin, J. (ed.) Architecture of Fear, pp. 48-52. Princeton, Princeton Architectural Press.

Hann, C. M. (1998) Property Relations: Renewing the Anthropological Tradition. Cambridge, Cambridge University Press.

Heiddeger, M. (1975) Poetry, Language Thought. New York, Harper Colophon.

Kohn, M. (2003) Radical Space: Building the House of the People. Ithaca, Cornell University Press.

Robbins, E. (forthcoming) Formalisation of Land and Housing Tenure to Empower the Poor: Simple Nostrum or Complex Challenge?, in: Banik, D. (ed.) Rights and Legal Empowerment in Eradicating Poverty. London, Ashgate.

Schirmer, J. (1994) The Claiming of Space and the Body Politic: Greenham Common Women and the Plaza de Mayo Mothers, in: Boyarin, J. (ed.) Remapping Memory. The Politics of TimeSpace, pp. 185-220. Minneapolis, University of Minnesota Press.

Sennett, R. (1976) The Fall of Public Man. New York, W. W. Norton.

Smith, N. (1996) The New Urban Frontier: Gentirification and the Revanchist City. London, Routledge.

Vidler, A. (1986) Scenes from the Street: Transformations in Ideal and Reality, 1750-1871, in: Anderson, S. (ed.) On Streets, pp. 29-111. Cambridge, MIT Press.

Young, I. M. (1986) The Ideal of Community and the Politics of Difference. Social Theory and Practice, 12(1).

Tonkiss, F. (2005) Space, the City and Social Theory. Cambridge, UK, Polity Press. 